would recoil, for many oribatid genera have been described uncritically. In presenting a catalogue of families and genera, and identification keys, Balogh has considered "every hitherto described family and genus (as) distinct" and synonymies, except the more obvious ones, have been ignored. This is bound to confuse "nonspecialist soil zoologists" for whom these keys are intended. The terminology used in the keys is straightforward and the author has taken pains to explain many of the technical terms, although the inclusion of a brief discussion of basic leg chaetotaxy would have been helpful. Identification keys are accompanied by code tables in which groups of similar genera are defined such that a genus may be distinguished from others in its group by simple comparison of certain quantitative features. These tables provide useful checks when used in conjunction with the keys, but the nomenclature devised to delimit the generic groupings will daunt the beginner. The illustrations, of which there are over a thousand, have been prepared to a standardized format and more than adequately complement the text.

There are avoidable errors, a few species wrongly attributed, and a disturbing tendency to introduce new family and genus names without any explanation. But the specialist will willingly live with these shortcomings in exchange for the wealth of information contained in this invaluable book.

JOHN A. WALLWORK

\section{Probability in Science}

Scientific Truth and Statistical Method. By Marcello Boldrini. Translated from the Italian by Ruth Kendall. Pp. xiv + 264. (Charles Griffin: London, January 1972.) $£ 5.40$.

THE philosophy of science is a notoriously unsatisfactory subject in the eyes of most scientists, for it neither portrays with accuracy how they argue, nor prescribes with conviction how they ought to argue. It is, in consequence, usually neglected by them, with the result that it becomes even more detached from the reality of scientific investigation.

It might have been supposed that the introduction of probabilistic reasoning in the eighteenth century would have provided the missing clue, but in fact it has greatly added to the richness of the discussion without bringing it perceptibly closer to a conclusion.

Some philosophers of science have neglected probability altogether, and only one, Dr Hacking in his Logic of Statistical Inference, has made a successful excursion into the real world of statisticians.
Professor Boldrini's work, now happily translated into English, suffers the disadvantage of having been written before Dr Hacking's was published in 1965. But the fields covered by the two books are more different than their titles suggest, Professor Boldrini's being less concerned with statistical method than scientific truth, and ranging widely over the whole of the philosophy of science. Indeed, at times it becomes a rather disconnected ramble round the celebrated names of the subject, with the attendant pleasure of a close examination of the wayside flowers tending to conceal the lack of progress in any particular direction.

The book is in five sections, "Science and Language", "Axioms", "Deduction and Induction", "Probability and Statistics", and "The Methodological Structure of the Natural Sciences".

There is no detailed discussion of the different points of view that continue to divide the statistical world, Professor Boldrini seeming somewhat reluctant to descend from the distant contemplation of theories of probability to the practical question of the validity of common statistical procedures. The basic rift between Bayesians and nonBayesians, which goes right to the bottom of the discussion on scientific truth and statistical method, is not given the importance it deserves, and Ramsey's work is nowhere mentioned. Professor Boldrini decides for himself "in a non-Bayesian sense", following which one might have expected a discussion of the differences between Fisher and the school of Neyman and Pearson, but there is no inkling that any such differences exist.

Most extraordinary is the absence of any evidence that the author was aware of the existence of Fisher's book Statistical Methods and Scientific Inference, published in 1956, in spite of the fact that he recommends Fisher and Karl Pearson as "eminent examples of original minds, from whom every statistician should draw inspiration". Perhaps, like Professor M. G. Kendall, he wished the book had never been written, or, like Professor D. V. Lindley, he found it a disappointment. We should like to bave known.

\section{A. W. F. EDwards}

\section{Live Ancient Monuments}

Crocodiles: Their Natural History. By C. A. W. Guggisberg. Pp. $x+195$. (David and Charles: Newton Abbot, March 1972.) £2.75.

Crocodilians do not attract much attention outside specialist circles, so I had not expected to see two general works on them appear within months of one another-the other is by Wilfred T.
Neill. Mr Guggisberg's work is more directly aimed at interesting the public and making a plea for conservation.

The twenty-two or so living species of crocodilians are described and their ranges indicated. There is a general account of the principal features of crocodilians and their evolution. The work is evidently addressed to nontechnical readers, and I wonder what they will make of such features as the figure of an alligator's brain with no particular relevance to the text or of the "considerable antero-posterior expansion" of the ilium.

The author is evidently very well read on crocodile lore. There are many interesting stories including numerous personal observations, mostly on the Nile crocodile. Some of these stories Neill regards as mythical-as, for example, that they knock down their prey with their tails and that old gharials have a swelling on the end of the snout. In this latter case, however, Guggisberg gives us a reference to a published photograph. In considering crocodiles as a hazard to human life Guggisberg concludes that a large proportion of accidents is due to the extraordinary nonchalance of people who live near crocodile infested waters. The author argues that a really serious threat to their survival has developed only recently as a result of a fashion for the leather. Conservation is discussed -I liked the suggestion that we should preserve crocodilians as one of the world's most ancient monuments.

GARTH UNDERWOOD

\section{Early Earth Science}

Earth Sciences. (The Royal Institution Library of Science, being the Friday Evening Discourses in Physical Science held at the Royal Institution 18511937). Edited by Stanley Keith Runcorn. Vol. 1: Pp. $x x+502$. Vol. 2: Pp. xvi+539. Vol. 3: Pp. xvi +499 . (Applied Science: London, 1971.) $£ 20$ the three volumes.

THIS three-volume work, totalling about 1,500 pages, presents a record of 135 Friday Evening Discourses delivered at the Royal Institution from 1851 to 1937 , on a particular group of subjects, the socalled Earth sciences. This term is now in use to include a number of specialized branches of science formerly comprised under the less cumbersome and equally comprehensive term geology. A rough breakdown of the subjects of the lectures shows that about eighty are likely to be of particular interest to geologists; thirty are on meteorology; a few are on oceanography, travel and exploration; and there are a small number on subjects that do not fall readily into any of these categories. In some 